\title{
“EVALUATION OF DRUG-DRUG INTERACTIONS IN PATIENTS OF GENERAL MEDICINE, ICU and EMERGENCY DEPARTMENTS AT A TERTIARY CARE HOSPITAL"
}

\author{
N. VANITHA JYOTHI ${ }^{*}$, BHARATHI D. R. ${ }^{2}$, PRAKRUTHI G. M. ${ }^{3}$ \\ 19harm D, Department of Pharmacy Practice, SJM College of Pharmacy, Chitradurga, Karnataka, India, 577502, 2 Professor \& Principal, \\ Department of Pharmacology, SJM College of Pharmacy, Chitradurga, Karnataka, India, 577502, 3Pharm D, Department of Pharmacy
} Practice, SJM College of Pharmacy, Chitradurga, Karnataka, India, 577502

Email: varshithasrireddy222@gmail.com

Received: 22 Jan 2018, Revised and Accepted: 08 Apr 2018

ABSTRACT

Objective: To evaluate the drug-drug interactions in General medicine, ICU and Emergency departments.

Methods: It is a prospective-observational study. This study included hospital In-patients treated in General medicine, ICU and Emergency. Data were collected from the medical records of In-patients which includes patient's demographic details, medical history, social history, treatment chart, status and drug-drug interaction is assessed by using Lexicompand Medscape and other tertiary resources and documented in a suitably designed data collection form.

Results: A total of 250 subjects were enrolled in the study. The majority (23.6\%) of cases were identified in the age group 51-60 y old. Higher rate of DDIs was identified in the male gender prescriptions. $70 \%$ moderate interactions, $33.6 \%$ Minor interactions, $6.4 \%$ serious interaction found in General medicine, ICU and Emergency departments.

Conclusion: Polypharmacy, age and comorbid condition were took part major role in drug-drug interactions.

Keywords: Drug-drug interaction, Significant, Minor, Serious interactions

(c) 2018 The Authors. Published by Innovare Academic Sciences Pvt Ltd. This is an open access article under the CC BY license (http://creativecommons.org/licenses/by/4.0/) DOI: http://dx.doi.org/10.22159/ijcpr.2018v10i3.27345

\section{INTRODUCTION}

Drug-drug interaction (DDI) may be defined as the pharmacological or clinical response to the administration of a drug combination that is different from the anticipated known effects of the two agents when given alone and that can result in reduced effectiveness or increased toxicity [1].

A DDI can be the consequence of various situations that reflect the growing number of drugs available in the market and increasing complexity of polypharmacy is a cause of DDIs. The very widespread practice of self-medication makes the situation more severe and difficult [2].

These may occur due to several reasons. For example, accidental misuse or younger people tend to metabolize drug faster than older people or those who smoke the cigarettes metabolize clozapine and olanzapine faster than those who do not. Comorbid medical condition that decreases the hepatic function, such as cirrhosis or congestive heart failure, are likely to decrease the rate of drug metabolism. CytochromeP450 enzymes are polymorphic, there exist ethnic differences in hepatic enzymes that influence the pharmacokinetics of drugs and also due to lack of knowledge about the active ingredients involved in the relevant substances. These processes may cause alterations in the pharmacokinetics of the drug, such as Absorption, Distribution, Metabolism, and Excretion (ADME) of a drug. Alternatively, drug interactions may be the result of the pharmacodynamic properties of the drug, e. g. the coadministration of a receptor antagonist and an agonist for the same receptor. Drug interactions are to be avoided, due to the possibility of poor or unexpected outcomes [3].

Hence, we conducted the study for assessing, monitoring and reporting of drug-drug interactions in a patient's prescriptions. This study was designed to investigate the occurrence and extent of drugdrug interactions in prescriptions of General medicine, ICU and emergency wards in a teaching hospital.

\section{MATERIALS AND METHODS}

\section{Study site}

This study was conducted at Basaveshwara Medical College and Hospital, Chitradurga.

\section{Study approval}

This study was approved by the "Institutional Ethical Committee" of the S. J. M College of Pharmacy, Chitradurga. (SJMCP/IEC/18/2016-17).

\section{Study design}

The study was designed majorly to investigate the drug-drug interactions in patients admitted in General Medicine, ICU and Emergency departments of a tertiary care hospital. Thus the study was described as a prospective observational study.

\section{Study period}

The study was conducted for a period of six months.

\section{Study subjects}

The study included hospital In-patients treated in General medicine, ICU and Emergency departments. Patient who met the following criteria were enrolled.

\section{Study criteria}

Inclusion Criteria

All inpatients prescriptions of general medicine, ICU and emergency department. Patients with critical conditions as per clinician opinion.

Data were collected from the patient's past $24 \mathrm{~h}$ of admission.

\section{Exclusion Criteria}

Outpatients. 


\section{Study procedure}

The study was conducted over inpatient wards of general medicine, ICU and emergency wards.

A pre-designed data collection form was applied to collect patient demographics, medical history, social history, and complete current therapy was recorded. Confidentiality will be maintained. Data were collected from the patients of past $24 \mathrm{~h}$. Collected prescriptions were analysed for drug-drug interactions by using databases like lexicomp, Medscape drug interaction checker, tertiary sources like Stockley's drug interactions checker etc. Serious, significant and minor interactions were judged by using Medscape drug interaction checker software.

\section{Statistical analysis}

The data was entered in Microsoft Excel-2010 version and the results were analysed using Statistical Package for Social Services (SPSS 19.0). Descriptive Methods was applied to obtain the frequency and percentage.

\section{RESULTS}

\section{Age}

Among 250 subjects $(\mathrm{n}=250)$ were 41 subjects belongs to age group below 30 , and 32 subjects belongs to age group between 31-40, and 33 subjects belongs to age group between $41-50$, and 59 subjects belongs to age group between $51-60$, and 46 subjects belongs to age group between $61-70$, and 30 subjects belongs to age group between 71-80, followed by 9 subjects included in age group above $80 \mathrm{y}$ old. The age group between 51-60 are more prone to drug-drug interactions.

\section{Gender}

Out of 250 subjects, 127 were males and 123 subjects were female. Males are more than females.

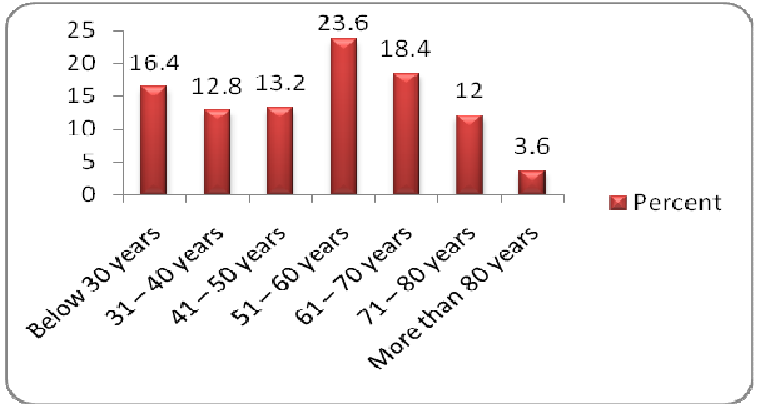

Fig. 1: Distribution according to age

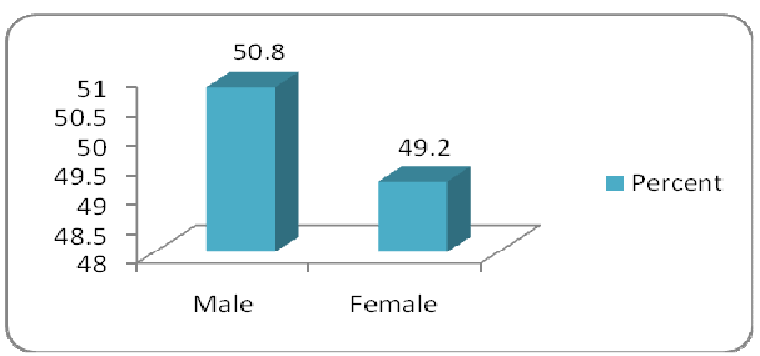

Fig. 2: Distribution according to gender

\section{Medical history}

Out of 250 subjects, 120 subjects were not having any medical history, and further as follows.

Comorbid conditions shows a significant effect on drug-drug interactions.

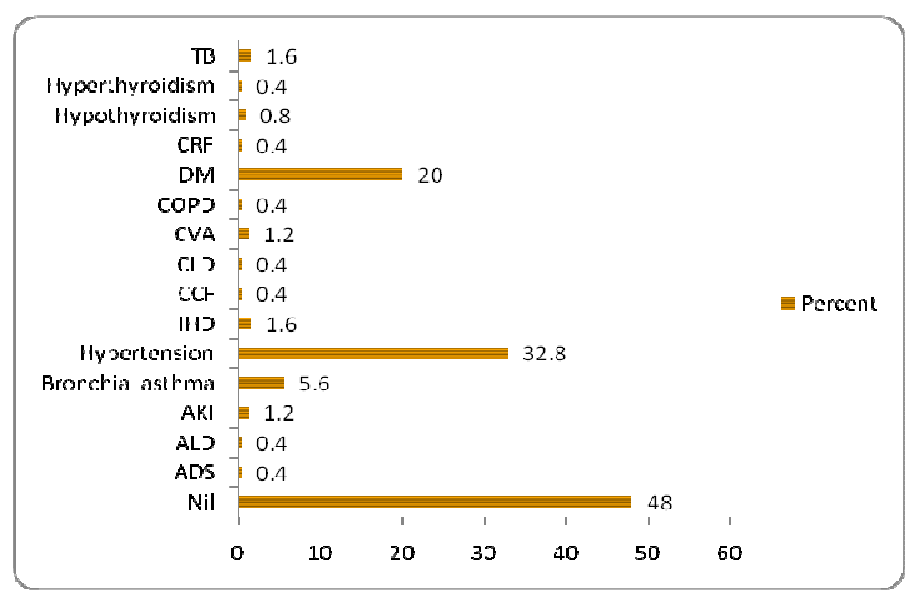

Fig. 3: Distribution according to medical history

Table 1: Distribution according to Number of drugs prescribed

\begin{tabular}{lll}
\hline No of drugs prescribed & Frequency & Percentage \\
\hline 3 & 2 & $.8 \%$ \\
4 & 11 & $4.4 \%$ \\
5 & 16 & $6.4 \%$ \\
6 & $16.0 \%$ & $30.0 \%$ \\
7 & 40 & $20.4 \%$ \\
8 & 75 & $12.8 \%$ \\
9 & 51 & $7.2 \%$ \\
10 & 32 & $0.8 \%$ \\
11 & 18 & $1.2 \%$ \\
Total & 2 & $100.0 \%$ \\
\hline
\end{tabular}


Table 2: Distribution according to no. of interactions

\begin{tabular}{lll}
\hline No of Interactions found & Frequency & Percentage \\
\hline 1 & 68 & $27.2 \%$ \\
2 & 51 & $20.4 \%$ \\
3 & 30 & $12.0 \%$ \\
4 & 34 & $13.6 \%$ \\
5 & 23 & $9.2 \%$ \\
6 & 9 & $3.6 \%$ \\
7 & 8 & $3.2 \%$ \\
8 & 14 & $5.6 \%$ \\
9 & 6 & $2.4 \%$ \\
10 & 6 & $2.4 \%$ \\
11 & 1 & $.4 \%$ \\
Total & 250 & $100 \%$ \\
\hline
\end{tabular}

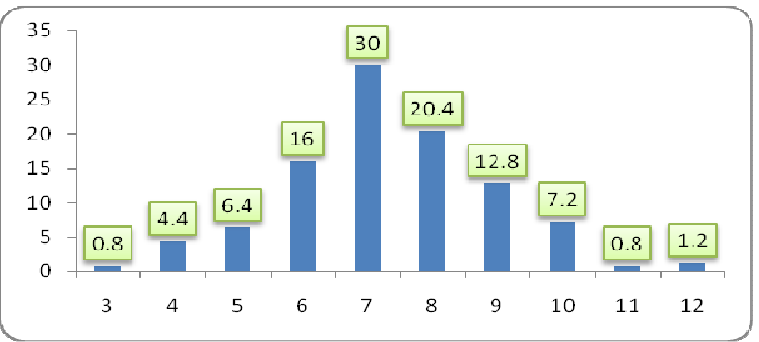

Fig. 4: Distribution according to Number of drugs prescribed

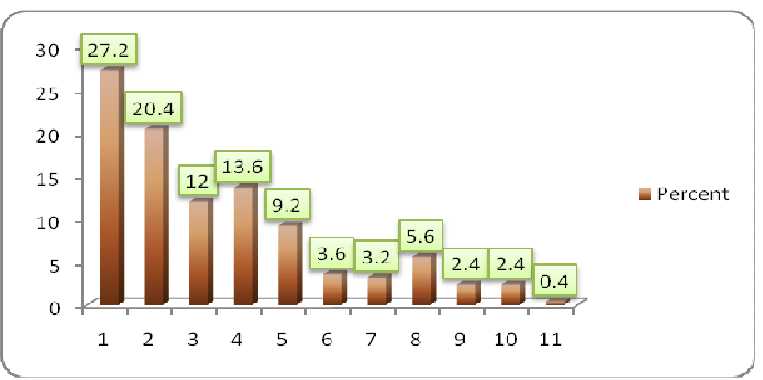

Fig. 5: Distribution according to no. of interactions

\section{Drug-drug interactions according to the severity}

The drug-drug interactions according to severity, among 250 subjects, we found 84 mild interactions, 175 moderate and 16 severe interactions.

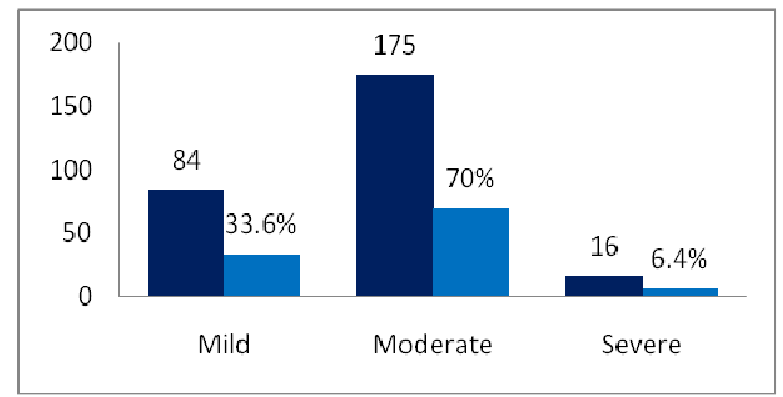

Fig. 6: Drug-drug interactions according to the severity

\section{Serious interaction}

Among 16 serious interactions, the artemether/lumefantrine with ondansetron and rabeprazole and clopidogrel found more and remaining interactions follows.

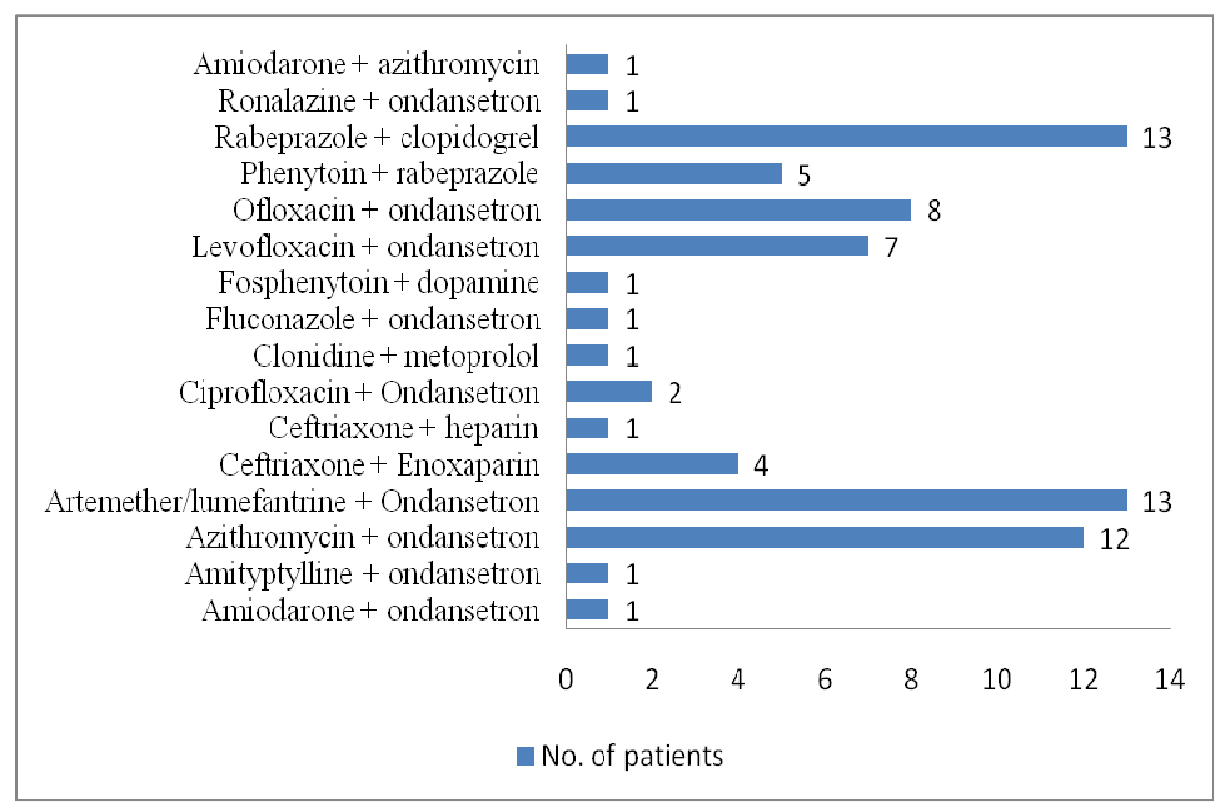

Fig. 7: Distribution of serious interacting drugs 


\section{DISCUSSION}

Ignazio $\mathrm{G}$ et al. the incidence of potential drug-drug interaction is close to $40 \%$ in subjects taking 5 drugs and $80 \%$ in subjects taking 7 or more medication. In our study, the incidence of drug-drug interactions among 250 subjects is, $30 \%$ in subjects taking 7 drugs, $20.4 \%$ in subjects taking 8 drugs $16 \%$ in subjects taking 6 drugs and $22 \%$ in subjects taking 9 or more medication. From this, it can assessed that chances of DDI will be more with polypharmacy.

Soherwardi S et al. says that The first 5 commonly observed major, moderate and minor interactions and their frequencies are, Ciprofloxacin+Insulin (17) Digoxin+Spironolactone (11), Spironolactone+Ramipiril (7) Atorvastatin+Niacin(6) Ciprofloxacin+ Theophylline (4). [56] In our study the common major interactions found were Rabeprazole+Clopidogrel (13) Artemether/ lumefantrine+ Ondansetron (13) Azithromycin+Ondansetron (12) Ofloxacin+Ondansetron (8) Levofloxacin+Ondansetron (7) Phenytoin+Rabeprazole followed by other drugs [7].

\section{CONCLUSION}

Based on the obtained results, our study concluded that: Subjects at the age group 51-60 y were developed a higher rate of Drug-Drug Interactions.

$50.8 \%$ of males and $49.2 \%$ of females are found with drug-drug interactions. Higher rate of polypharmacy was identified in male gender.

Comorbid conditions have a significant effect on drug-drug interactions.

Most patients were shown DDI when more number of drugs are prescribed. Polypharmacy has a significant effect on drug-drug interactions.

The following classes of drugs were majorly identified in our study. a) proton pump inhibitors, b)antimalarial, c)antiemetics, d)bronchodilators, e)antihypertensives, f) antibiotics, g)analgesics, h)anticoagulants.

Careful timing of drug administration is very important to prevent the Drug-Drug interactions and potential problems.

\section{AUTHORS CONTRIBUTIONS}

All the author have contributed equally

\section{CONFLICT OF INTERESTS}

Declared none

\section{REFERENCES}

1. Sheldon H, Preskorn, David F. Guide to psychiatric drug interactions; 2006;13:35-64.

2. Glintborg B, Andersen SE, Dalhoff K. Drug-drug interactions among recently hospitalized patients-frequent but mostly clinically insignificant. Eur J Clin Pharmacol 2005;61:675-81.

3. Souza JMC, Thomson JC. Prevalence of potential drug-drug interactions and its associated factors in a Brazilian teaching hospital. J Pharm Pharm Sci 2006;9:427-33.

4. Nazariab AM, Moqhadam KN. Evaluation of pharmacokinetic drug interactions in prescriptions of intensive care unit (ICU) in a teaching hospital. Int J Pharmacol Res 2006;3:215-8.

5. Rafi SM, Naqvi SBS, Khan UM. Evaluation of potential drug-drug interactions with antidepressants in two tertiary care hospitals. J Clin Diagnostic Res 2015;9:FC05-FC08.

6. Barot AP, Malhotra DS, Patel JP. Evaluation of potential drugdrug interactions in patients of the emergency medicine department at a tertiary care teaching hospital: a prospective study. Int Study Sci Study 2015;3:48-53.

7. Soherwardi S, Chogtu B, Faizal P. Surveilance of the potential drug-drug interactions in the medicine department of a tertiary care hospital. J Clin Diagnostic Res 2012;6:1258-61. 